\title{
João Guimarães Rosa: Língua e Estilo
}

\begin{abstract}
figura de João Guimarães Rosa sobressai no mundo da literatura A brasileira contemporânea. Suas quatro obras já publicadas - $S a$ garana (1946), Corpo de Bailel (1956), Grande Sertão: Veredas (1956), e Primeiras Estórias (1962) - têm excitado tanto os leitores quanto os críticos como só as de Mário de Andrade e os modernistas dos '20, e a sua presença literária, como a dêles, marca época. Exemplo típico da reação criada por cada uma das obras toseanas é o seguinte comen. tário do crítico Affonso Ávila, escrito quando surgiu o romance épico Grande Sertãa: Veredas:
\end{abstract}

O livro caiu impiedosamente sôbre a desoladora pobreza de nossa ficção pós-modernista, exaurida pelo mais estéril formalismo, desorientada pela imprecisão da crítica escolástica ....

Ele desprezou a lição do romance nordestino para estribar-se na experiência pessoal ....

O elemento poético nasce livre de artifício literário, as imagens brotam da terra mesma em forma de pássaros, árvores, rios, num animismo impregnado de emoção e imprevisto ....

O que ... impressiona sobremaneira nêsse homem privilegiadamente talentoso é ter êle recriado no plano artístico, sem perverter as suas fontes, a língua prodigiosa do sertão ...., imprimindo-lhe a mesma flexibilidade que the dá o sertanejo eloqüente, imaginoso. Que romancista mais autênticamente nacional, portanto, que êsse primitivo Guimarães Rosa?1

1 Affonso Avila, "A autenticidade em Guimarães Rasa", O Estado de S. Paulo, Suplemento Literário (12 janeiro, 1957). 
Nem sempre a reação dos críticos perante a obra do autor tem sido tão favorável como a de Ávila. Existe também considerável comentário adverso, principalmente por causa da iconoclastia sintática de Guimarães Rosa, de seu emprêgo de neologismos, e da inovação estrutural de certas obras de maior extensão. Ele é acusado de obscuro, artificial, e lúdicro, até de confuso e ilegível. Mesmo os detratores, contudo, consideram-lhe a obra com certo respeito, pois a sua alta categoria de lestilista é visível através do nevoeiro de incompreensão, e é preciso tê-la em conta.

A carreira literária dêste homem extraordinário, também diplomata e médico, vem se desenvolvendo deste a década dos '30. Entre os meses de junho e dezembro de 1937 compôs quase uma dúzia de contos do sertão mineiro, e é daquela época que se pode datar a sua iniciação como escritor maduro e original. Os contos antigos escritos durante os anos de Faculdade foram concebidos segundo os padrões e técnicas tradicionais derivados de outros autores já estabelecidos do gênero, mas de 1937 para diante começam a aparecer o vigoroso estilo e interpretação que agora reconhecemos como marcas do autor. Publicou Guimarães Rosa a maioria dos contos daquêle ano quase uma década depois ( I946) num volume intitulado Sagdrana. A obra recebeu imediatamente a aclamação do público e dos críticos e ganhou o prêmio da Sociedade Felipe d'Oliveira; está atua'lmente na sexta edição. Estas histórias sertanejas de Minas ("O burrinho pedrês," "A volta do marido pródigo," "Sarapalha," "Duelo," "Minha gente," "São Marcos," "Corpo fechado," "Conversa de bois," e "A hora e vez de Augusto Matraga") apresentam de uma maneira viva e simpática a gente, os animais, a paisagem, e os problemas do sertão, revelando a profunda absorção do autor na sua matéria e a sua empatia com as personagens que cria ou lembra de entre os seus conhecidos do passado. Sagurana pôde excitar o público, porém, por razões adicionais ao seu conteúdo; seu maior efeito resultou da originalidade estilística e da reprodução de elementos do vocabulário e sintaxe regionais ainda não utilizados em literatura.

Durante os anos 1953-55 experimentou Guimarães Rosa uma fase incrìvelmente prólífica, durante a qual compôs simultâneamente suas duas obras mais extensas e complexas - Corpo do Baile e Gronde Serião: Veredas. Compreende Corpo de Baile uma sétie de sete novelas, intituladas respectivamente "Campo geral," "Uma estória de amor," "A estótia de Lélio e Lina," "O recado do morro," "Dão-lalalão," "Cara-de-bronze," e "Buriti." Ao passo que as histórias de Sagararta são independentes uma da outra, existem entre as novelas de Corpo de Baile certas relações, principalmente no que se refere a algumas das personagens, cujo desenvolvi- 
mento podemos seguir em várias etapas da série. A primeira edição desta extensa obra apareceu em dois volumes; a segunda, publicada em r960, foi condensada num só tomo. Ultimamente temos a terceira edição em três volumes mais curtos e de títulos diversos: Manuelzão e Miguilim, No Urubriquaquá, no Pinbém, e Noiffes do Seriáa.

Grande Sertão: Veredas, também na sua terceira edição (1963), é considerado a mais impressionante criação de Guimarães Rosa, tanto do ponto de vista da pura extensão da obra (quase 600 páginas) quanto do conteúdo e apresentação da matéria, elementos que constituem uma espécie de tour de force épico. No ano mesmo da sua publicação ganhou o "Prêmio Machado de Assis" do Instituto Nacional do Livro e desde então tem sido um blest seller no Brasil. Em I963 foi traduzido em inglês por James. L. Taylor e Harriet de Onís com o titulo The Devil to Pay in the Back-lands; embora bem coloquial, exprime êste título a essência da obra, cuja temática central versa um suposto pacto com o Diabo feito por um jagunço para matar outro chefe rival.

Durante o ano de I96I-2, uns seis anos depois da publicação de Corpo dé Baile e Grande Sértão, compôs Guimarães Rosa uma série de contos breves, os quais vieram a ser publicados em I962 debaixo do título de Primeiras Estórias. Este volumezinho de vinte e duas histórias gozou de tal popularidade que no ano seguinte saiu em segunda edição. Já que as Primeiras Estórzas constituem a obra mais recente publicada pelo autor, seu título pode parecer um pouco paradoxal; mas acontece que Guimarães Rosa considera êste volume o primeiro duma fase da sua obra que difere em certos aspectos daquela representada por Sagarana, Corpo de Baile, e Grande Sertão: Veredas. Depois da aparição das Primeiras Estóricas, o autor não ficou na inatividade; pelo contrário, tem vindo da sua pena um número considerável de contos e novelas para serem publicados individualmente em jornais e revistas, mas que até hoje não foram reunidos em volume.

No que diz respeito aos traços lingüísticos da obra de Guimarães Rosa, podemos voltar a nossa atenção a três principais áreas de interêsse: (r)o léxico, (2) a gramática e sintaxe, e (3) as técnicas poéticas e retóricas.

Em matéria de recursos léxicos do autor vemos que a riqueza e variedade das suas fontes e a sua originalidade na invenção de novas formas à base das antigas o colocam bem dentro da tradição de inovadores lingüísticos como James Joyce e Mário de Andrade. Embora existam tantas semelhanças e seja facílimo traçar as linhas paralelas entre êstes 
escritores, não devemos exagerar a dívida de Guimarães Rosa aos seus antecessores à custa do seu próprio talento criador. Ele mesmo comenta assim a sua atitude com relação à obra de Joyce e Mário:

Não parto de predeterminações. Jamais tive programa ou "plataforma," quanto à linguagem, ou à técnica literária. Simplesmente escrevo .... De Joyce, só li parte do "Dubliners." O "Ulysses," fiz várias tentativas, que nunca foram além de pedaços de páginas. Acho nêle um ludismo, uma atitude que não me é simpática, excessiva intericionalidade formal, muitíssimo de "voulu," que me repele .... Mário de Andrade, polêmico, ligado a um Mơvimento, partiu de um desejo de "abrasileirar" a todo custo a língua, de acôrdo com postulados que sempre achei mutiladores, plebeizantes e empobrecedores da língua, além de querer enfeiá-la, denotando irremediável mau-gôsto. Faltava-lhe, a meu ver, finura, sensibilidade estética $\ldots .{ }^{2}$

Guimarães Rosa, apesar da sua sólida erudição, tem a vantagem de ser um "homem do povo" num sentido sem paralelo no caso de James Joyce nem no do Mátio de Andrade. Mas o que lhe distingue principalmente o estilo lingüistico do de Joyce ou Mário é a modlaraçãa. Os recursos potenciais de todos três são surpreendentemente semelhantes, mas Guimarães Rosa, além de se preocupar com o aspecto formal da obra literária e com a liberdade expressiva, é guiado (e às vezes refreado) por seu compromisso fundamental com a comunicação, fator concisamente avaliado por Augusto de Campos:

Em Guimarães Rosa nada ou quase nada parece haver de gratuito. As mais ousadas invenções lingüísticas estã̃o sempre em relação isomórfica com o conteúdo. ${ }^{3}$

Um dos fatores constantes do estilo léxico do autor é a justaposição e interação de elementos eruditos e coloquiais, com um balanço a favor dêstes últimos nas obras predominantemente rurais (Sagarana, Corpo die Baile, e Grande Sertão: Veredas) e um equilíbrio entre os dois nas Primèiras Estórias. Combinam-se arcaismos, regionalismos, latinismos, palavras científicas e estrangeiras em mistura com vocábulos mais correntes; esta

2 Carta do autor, 3 de novembro de 1964.

3 Augusto de Campos, "Um lance de 'dês' do Grande Sertão", Revista do Livro. No. 16 (dezembro, 1959), p. 17. 
harmoniosa coexistência de elementos variados contribui para um léxico integrado que é escencialmente brasileiro sem ser estreitamente regional e que exige a atenção do leitor mais perspicaz sem ser excessivamente erudito. Esta interrelação de componentes vocabulares encontra a sua contraparte na área de conceito e conteúdo, na preocupação do autor pelas facetas diversas e entrelaçadas da realidade experiencial da existência humana.

A procura incessante do mot juste de parta de Guimatães Rosa e a sua paixão pela condensação e concisão dos meios expressivos levam-no à invenção de numerosos neologismos, os quais se integram no seu léxico funcicnal e em muitos casos constituem verdadeiras marcas características da sua prosa. $\bar{E}$ nesta área neologista que podemos considerar o autor como renovador da língua portuguêsa, mas renovador sempre fiel ao caráter essencial e ao desenvolvimento histórico dessa língua, pois o seu padrão inventivo consiste na modificação parcial de palavras comuns para thes dar vida nova e significado mais penetrante. Oswaldino Marques descrevenos seguintes têrmos os motivos do autor na sua função de inovador léxico:

Sua função primordial ... é descondicionar os nossos hábitos verbais e levar-nos a reexperimentar as idéias ou sensações veiculadas. A comoção que nos agita arranca-nos, por assim dizer, à nossa letargia mental e nos obriga a repensar os objetos. A linguagem opera, dêsse modo, a contínua reativação das nossas vivências e nos abastece de conotações insuspeitadas .... O seu objetivo é desviar sua criação do trânsito ideativo totineiro e compeli-la a freqüentar novas pistas de invenção. ${ }^{4}$

$\mathrm{O}$ assunto neologista nos leva a comentar um segundo aspecto da obra roseana $\longrightarrow$ Os seus traços sintático-gramaticais. Estes são, em têrmos de resumo, os seguintes:

Além dos neologismos formais do seu léxico, o autor cria efeitos neologistas pelo emprêgo original de várias categorias gramaticais (sobretudo os adjetivos) em tipos inesperados de ligação que resultam na amplificação semântica e em freqüentes efeitos sinestésicos: $\overline{\mathrm{E}}$ iconociasta a atitude de Guimarães Rosa perante as tradicionais categorias gramaticais, revelando um desprêzo quase primitivo pelas barreiras que separam as funções de cada cat gooria. Em benefício da comunicação expressiva êle permite a interfunção de gerúndics e particípios e a apropriação por certas categorias verbais das funçōes de outras; encontramos, por exemplo, adje-

4 Oswaldino Marques, A seta e o alvo (Rio de Janeiro, 1957), pp. 82-3. 
tivos que funcionam como advérbios, advérbios como adjetivos, substantivos como adjetivos e advérbics, pronomes como substantivos nominais, etc. Emprega-se singularmente a técnica de substantivação de elementos não nominais, o que enriquece o estilo já essencialmente nominal do autor por meio da adição de uma série de conceitos novos.

Empregam-se largamente na obra roseana pares derivativos para efeitos intensivos; entre outras duplicaçōes freqüentes figuram o emparelhamento de elementos sinônimos e a justaposição de pares não relacionadas com o fim de sugetir uma comparação condensada (nas categorias nominais e adjetivais) ou a implícita simultaneidade (no caso dos verbos). É também freqüente o emprêgo puramente pleonástico, sobretudo no caso de negativos usados para ênfase especial.

$\mathrm{O}$ autor desfruta de grande liberdade no emprêgo de artigos, utilizando-os frequirentemente como elementos redundantes e, ainda mais comumente, omitindo-os completamente. A atrição dos artigos serve os fins contrastantes de barbarização e poetização da prosa roseana.

O emprêgơ de ocasionais concentrações, ou cacbos, de substantivos, adjetivos, ou verbos serve para produzir interêsse ou intensidade especial nos trechos em que se empregam e oferece um relêvo contrastante com a prosa corrente do seu contexto.

A escolha dos tempos verbais nas narrações roseanas varia de um volume para outro segundo a natureza das obras mesmas. Emprega-se mais consistentemente o tempo imperfeito em Corpo de Baile. Grande Sertão: Verodas e as Primeiras Estórias dão preferência igual ao imperfeito e ao pretérito, ao passo que Sagarana combina êstes últimos com o presente histórico. $\mathrm{O}$ imperfeito do subjuntivo desempenha um papel distintivo em tôdas as obras menos Sagarana, tanto num emprêgo intensivo dentro da função subjuntiva tradicional como em outras funções também.

Apresenta-se o diálogo em forma direta por via de regra, e se integram trechos conversacionais dentro da narrativa por meio de uma variedade de construções empregadas como "ponte."

Entre as técnicas literárias mais afastadas do emprêgo popular ou corrente é a inversão de elementos fraseológicos para criar uma prosa bem diferente da típica narrativa em língua portuguêsa. Tais inversões flutuam desde a simples transposição de elementos individuais com relação às palavras que as governam até às modificações sintáticas em grande escala. Desde tênues comêços em Sagarana, aumentam-se as inversões para atingir a sua maior freqüência em Grande Siertão: Veredas e depois se nivelarem. A inversão de frases serve como veículo muito útil na terminação de cláusulas, sobretudo por meio de transposição de verbos para o fim de frases. 
As inversões se empregam outrossim para efeitos enfáticos ou nóveis, mas a sua presença resulta muitas vêzes em dificuldades de leitura.

Construções parentéticas de vários tipos servem bem na fabricação de frases concisas e condensadas que refletem simultâneamente múltiplas facetas da realidade e prestam à narrativa um caráter vigoroso e colorido. $\mathrm{O}$ tipo mais comum de construção isolada do resto da frase é o adjetivo quase- aposicional depois de un substantivo, embora existam outros tipos também.

Em matéria de subordinação, mostra o autor clara preferência pelas frases participiais e as construçōes absolutas em vez das cláusulas completas, outro indício da sua tendência de favorecer a mais compacta dentre formas alternativas.

As frases participiais ficam muitas vêzess em posição independente como entidades frasais, como também as cláusulas dependentes introduzidas por pronomes e advérbios relativos ou conjunçōes subordinadas. Tais construções truncadas podem ser, em última análise, um esfôrço subconsciente por parte do autor para evitar a complexa hipotaxe pelo simples expediente de dividir as frases compridas em meias-frases curtas.

A pontuação roseana é, em face das normas tradicionais, bastante caprichosa. Mostra um emprêgo excessivo da vírgula, a desvalorização de outros sinais convencionais pelo uso constante, e uma correspondência geral às inflexões da expressão oral em vez da lógica gramatical da prosa escrita. A preocupação do nosso autor com a pontuação reflete com fidelidade o caráter predominantemente linear, coordinativo, do seu estilo paratático.

Ocorre normalmente nos textos roseanos o assíndeto, mas às vezes aparecem concentrações polissindéticas como reflexo do uso oral. Outros tipos elípticos na obra do autor incluem a atrição de numerosos elementos atônicos (e.g., conjunções subordinadas, preposições) e de verbos copulativos. Tais omissões resultam em freqüente rompimento na lógica das frases, deixando para o leitor o suprir das ligações que faltam; a autor se interessa mais pelas próprias entidades gramaticais constituintes das frases do que por sua interrelação hierárquica.

Típica da estrutura e equilíbrio das frases roseanas é uma espécie de sintaxd telégráfica, produto da elaboração dos elementos sintáticos já mencionados. Embora seja êste o tipo mais comum de frases e parágrafos por tôda a sua obra, refletindo assim a sua característica economia verbal, mostra o autor grande sensibilidade e versatilidade no matrimônio de forma e conteúdo nạ sưa estrutura sintática e varia a inflexão, extensão, 
e equilíbrio das frases de acôrdo com os seus princípios de comunicação expressiva.

Igual ao léxico roseano, a sua sintaxe mostra a constante interação de tendências eruditas e coloquiais. Em contraste com o equilíbrio no seu vocabulário, porém, evidencia esta sintaxe a predominância de tendências literárias e eruditas empregadas com grande originalidade para criar uma maneira pessoalíssima de expressão. E a gramática roseana, mais do que o léxico, que desalenta uma parte considerável do público. A sua torrente incessante de prosa exige muito do leitor-ouvinte, que não pode relaxar a sua atenção durante um só momento sem arriscar a perda de uma palavrachave ou relação vital. Ê sobretudo o carácter paradoxicalmente belo e grotesco, o dinamismo já lírico, já bàrbaramente primitivo do seu estilo que merece a denominação de burroca e faz da prosa roseana um caso singular na arte romanesca do Brasil contemporâneo.

Através de quase tôda a sua obra, aproveita Guimarães Rosa uma série de técnicas poéticas e retóricas: ritmo, rima (às vezes completa, outras vêzes assonante ou consonante), aliteração, onomatopéia, repetição, elipse, perguntas retóricas, digressão narrativa, diálogo estilizado, e outras técnicas a estas relacionadas. Por meio do hábil emprêgo dêstes recursos, obtêm verdadeiro sucesso na criação de uma prosa que exprime ao mesmo tempo os sentimentos e os fatos, indo além do prosaico para se tornar elemento de inerente musicalidade e beleza. Para se experimentar e apreciar, contudo, esta prosa deve ser lida em voz alta ou pelo menos imaginada no "ouvido mental" do leitor, pois tem base essencialmente oral. As personagens costumam exprimir oralmente os seus problemas e ambições, revelando-se tão plenamente no que dizem como no que fazem. As narrativas de Riobaldo na primeira pessoa e dos outros muitos narradores-protagonistas que aparecem nos contos e novelas do autor exigem dos ouvintes a sua completa atenção a cada palavra daquêle que fala, por sinuosa que seja a sua linha narrativa. Desta maneira Guimarães Rosa, com o seu estilo oral ao mesmo tempo linear e ornado, angular e sonoro, primitivo e poético, dinâmico e magestoso, se coloca bem dentro da veneranda tradição dos contadores de estórias de tôdas as épocas. Não são fortuitas as evocações medievais por tôda a obra dêle, pois no estilo roseano se revela a mesma arte espontânea, criadora, mas ao mesmo tempo 
quase ritualista, dos cantadores de baladas, aquêles que memorizaram e transmitiram a literatura do mundo desde tempos imemoriais.

Após um exame das variadas facetas léxicas, gramaticais, sintáticas e poéticas da prosa de Guimarães Rosa — das quais os comentários anteriores servem só de breve resumo- podemos tirar certas conclusões gerais a respeito do seu estilo lingüístico. Notamos a sua estima quase mística pelas palavras ptor se como entidades invioláveis de som e personalidade além de símbolos significantes. Com a sua mente original a trabalhar com recursos lingüísticos tradicionais, Guimarães Rosa desenvolve um léxico integrado, híbrido, incorporando e sintetizando elementos os mais diversos com alto grau de seleção e sensitividade. Consegue revitalizar padrões morfológicos bem familiares e embarca com efeito num programa de renovação léxica que realiza muitas das proposições feitas anteriormente por Mário de Andrade sem cair no doutrinarismo dêste. Escreve Guimarães Rosa com uma espontaneidade ao mesmo tempo refrescante e desnorteadora. Em todos os aspectos da sua obra se nota uma falta de rigidez; a sua preocupação com a liberdade de forma e expressão não o leva, porém, a uma excessiva falta de elementos formais nem a uma complexidade cmpolada. A sua prosa, embora na primeira leitura aparentemente complexa e difícil, se mostra essencialmente simples, apropriando um estilo linear, paratático, baseado numa sucessão de unidades curtas e pontuado segundo a inflexão da voz. Guimarães Rosa procura e consegue uma prosa sucinta, condensada, e dinâmica tanto no seu conteúdo quanto na sua forma, e quando o português corrente carece de palavras para transmitir a nuança ou impressão exata que deseja comunicar, não hesita em criar neologismos próprios. Os seus neologismos, contudo, são sempre baseados na tradição lingüística portuguêsa e por esta razão não são totalmente estranhos ao leitor. Vê-se que o autor repete muitas vêzes processos e tendências fonológicos e morfológicos normais ao português arcaico, revelando-se assim profundamente versado nos aspectos históricos da língua.

E na área da sintaxe que a prosa roseana difere mais marcadamente dos padrões tradicionais para ser quase um caso único na ficção brasileira contemporânea. As liberdades aproveitadas por Guimarães Rosa salvam o seu estilo da monotonia da típica prosa pouco acidentada mas ao mesmo tempo criam certo grau de dificuldade para o leitor mais acostumado com os padrões correntes. A sintaxe do autor é eminentemente expressiva e 
flexível, mas, como resultado da sua natureza fortuita ou "telegráfica" pode considerar-se a maior pedra de tropêço da sua prosa para o leitor típico. A erudição de Guimarães Rosa se mostra claramente no seu tratamento da gramática e sintaxe, mas está sempre em interação subjetiva com certos elementos coloquiais.

Existe no estilo do autor um paradoxo inerente, pois ao passo que se desenvolve segundo linhas essencialmente orais, regionalistas, possui um tom claramente retórico, freqüentemente de elevada qualidade poética. Daí a aparente falta de coincidência entre certos elementos da prosa roseana - contraste entre a simplicidade bárbara das suas personagens por um lado e a delicada artificialidade de muitas das suas técnicas poéticas e retóricas por outro. E, contudo, êste mesmo paradoxo de tom, também evidente nos variados níveis de vocabulário empregados pelo autor, que fascina tanto o leitor e o mantém sempre alerta para o inesperado. Esta multifacetada interação de contrastes é relevante outrossim à preocupação do autor com a experiência e descrição de aspectos múltiplos e simultâneos da realidade. As suas obras não devem ser lidas e estudadas como contos e romances puramente realistas, pois fica sempre presente certo elemento surrealista que foge à análise. Assim, pois, há uma constante tensão interna nas obras roseanas, um esfôrço dinâmico que se revela na caracterização como também na sua sintaxe torturada, suas criações expressivas e as técnicas estruturais tão pouco comuns.

Evita Guimarães Rosa a estreiteza confinante do regionalismo, o plate aut do emprêgo comum, e a exclusividade subjetiva da linguagem poética esotérica por meio da integração de todos três elementos num instrumento lingüístico singularmente flexível e artístico que possui significado e eficácia globais. Já que é esta linguagem uma coisa eclética que não se mantém completamente fiel a nenhum nível nem área lingüísticos, pode-se considerar estilizada, artificial; cumpre assim a descriçãa feita vários anos atrás por Mário de Andrade na sua demanda de uma linguagem literária brasileira: "Se trata de sistematização culta e não fotografia do popular ... Essa sistematização tem de ser fatalmente pessoal." 5

O processo de transformar uma linguagem real em uma ideal implica a constante intervenção de seletetividade e modificação, a omissão de certos elementos e a inclusão de outros com vista ao contínuo e gradual melhoramento e embelezamento do original. Observa-se esta tendência também em outros aspectos do seu artesanato romanesco, como as caracterizações que

5 Mátio de Andrade, Cartas a Manuel Bandeira (Rio de Janeiro, 1958), p. 87. 
transformam sertanejos comuns em poetas e chefes de jagunços (e.g., Riobaldo) em paladinos. É básico na interpretação da sua obra o processo ascensional que reconhece a existência simultânea de vários níveis da realidade mas se esforça inevitàvelmente para alcançar o mais alto, o mais perfeito dêles. Numa carta dirigida à Sra. Harriet de Onís com relação à sua tradução de Sagarana em inglês, Guimarães Rosa esboça nos seguintes têrmos o significado potencial que visa para as suas téenicas lingüísticas:

Nos meus livtos ... tem importância, pelo menos igual ao do sentido da estória, se é que não muito mais: a poética ou poeticidade da forma, tanto a "sensação" mágica, visual, das palavras, quanto a "eficácia sonora" delas; e mais as alterações viventes do ritmo, a música subjacente, as fórmulas-esqueletos das frases -transmitindo ao subconsciente vibrações emotivas subtis. Tudo em 3 planos (como os ensinos das antigas teligiões orientais):

$$
\begin{aligned}
& \text { I. - the underlying charm (enchantment) } \\
& \text { 2.-the level-lying common meaning } \\
& \text { 3.-the "overlying" idea (metaphysic) }{ }^{6}
\end{aligned}
$$

Da mesma maneira em que o conceito roseano da realidade e do seu próprio artesanato implica uma progressão e compreensão neoplatônicas, assim também o seu desenvolvimento como estilista literário segue essencialmente o mesmo caminho. Vemos freqüentemente os contrastes entre as obras predominantemente "rutais" do autor (Sagarana, Corpa de Barle, e Grande Sertão: Veredas) e as cosmopolitas Primeiras Estórics quanto ao seu caráter e técnica; ficam estas um pouco àparte daquelas em possuir a mais alta percentagem de neologismos abstratos e a mais baixa de substantivos coletivos de tipo original, em mostrar uma notável variedade de sufixos diminutivos e alta incidência de verbos pós-adjetivais, substantivos pós-verbais, e palavras portmantedur, em fazer pouco uso de onomatopéia e versificação em contraste com o seu emprêgo concentrado de aliteração e da técnica da "palavra puxa palavra," e em colocar relativamente pouca ênfase no diálogo como recurso no desenvolvimento do enrêdo. As Primlaipas Estórias figuram como a menos oral e mais literária (no sentido de prosa escrita) das quatro obras do autor, aproveitando em mais alto grau os efeitos tradicionais da prosa $e$ as técnicas ensaísticas eruditas.

6 Carta datada de 9 de fevereiro de 1965. 
Para não dar a impressão de que existe em todo aspecto uma dicotomia entre o mais recente dos volumes roseanos e os anteriores, devemos lembrar que na maioria dos casos as mudanças que notamos no estilo do autor através dos seus trinta anos de escritor se desenvolvem pouco a pouco e não ocorrem tôdas de uma vez. O que vemos em geral é um esquema tripartido da organização dos 'contos e romance de Guimarães Rosa desde um ponto de vista lingüístico, considerando cada década da sua carreira literária até ao momento (I937-I966) como etapa dela. O seu estilo se faz cada vez mais complexo e inovacional desde os primeiros contos até Corpo de Baile e Grande Sertäa: Veredas, para depois se simplificar de várias maneiras nas Primeiruás Estórias. Após a simultânea aparição das duas extensas obras da década dos ' 50 , os críticos se perguntavam até que ponto iria o autor nas suas inovações lingüísticas sem se tornar simplesmente repetitivo ou tão esotérico que perderia grande parte do seu público de leitores. O próprio Guimarães Rosa respondeu a esta pergunta por meio da depuração e simplificação do seu estilo de uma forma que não diminui a sua originalidade mas aumenta o potencial comunicativo e o salva da excessiva préciosité. No delicado equilibrio entre a reação à opinião pública e a realização das exigências do gênio criador se descobre pelo menos uma parte do segrêdo do sucesso do Guimarães Rosa escritor. Resta ainda ver o que revelará o futuro sôbre o seu desenvolvimento estilístico, e êle mesmo recusa prognósticos a respeito. Em todo caso, o desenvolvimento tripartido pelo qual já tem passado o seu estilo é bem paralelo à sua interpretação em três níveis da sua obra em geral. Em Sagarana predomina o "underlying charm" do atrativo auditivo revelado no seu ritmo, rima e criação neologista. Em Corpo del Baile e Grande Sertão: Venedas vem à frente o "level-lying common meaning" da concentração sintática e desenvolvimento mais amplo do enrêdo e das personagens, ao passo que na maioria das Primeiras Estórias se difunde de forma penetrante a "overlying idea" ou elemento metafísico. Apesar do seu título um pouco enganador, apresenta esta última coleção a obra mais profunda e madura do autor, tratando em forma sucinta os conflitos e arrebatamentos do espírito humano no seu caminho ascensional. O fato, porém, de serem escritas várias estórias da coleção numa veia satírica e alegre presta à obra total um tom desigual; por isso, para a maioria dos leitores é Grande Seraão: Vkedas, em que se desenvolvem plenamente vários problemas de caráter existencial, que fica como o maior sucesso da carreira literátia do autor. 
Em conclusão, qual é a contribuição de Guimarães Rosa à língua e literatura brasileiras? A resposta consiste essencialmente em três palavras: renovação, flexibilidadle e universalidade. Por meio da revitalização de padrões morfológicos familiares, chama a atenção para o valor inerente e o potencial da palaurct, e por meio da sintaxe original e dinâmica e o sensível emprêgo de técnicas poéticas e retóricas, cria uma prosa de beleza estética e poder expressivo. Com relação à literatura mundial, êle desempenha o papel de "regionalista internacional" que consegue universalizar uma região (Minas Gerais) e um modo de vida cujo interêsse ficava antes essencialmente no campo das pesquisas sociológicas e da côr local. Nas palavras de Antônio Cândido:

A experiência documentária de Guimarães Rosa, a observação da vida sertaneja, a paixão pela coisa e o nome da coisa, a capacidade de entrar na psicologia do rústico, - tudo se transformou em significado universal graças à invenção, que subtrái o livro da matriz regional, para fazêt-lo exprimir os grandes lugares comuns, sem os quais a arte não sobrevive: dôr, júbilo, ódio, amor, morte, para cuja órbita nos arrasta a cada instante, mostrando que o pitorêsco é accessório, e, na verdade, o Sertão é o Mundo.7

$\mathrm{Na}$ sua estilização do popular e na universalização do regional, Guimarães Rosa desempenha papel vital tanto na vida interna das letras brasileiras quanto na crescente importância desta literatura nacional na cena mundial. A sua obra futura merece atenção, pois pode bem ser êste nosso autor um líder em novos rumos e um dos grandes escritores da literatura brasileira do século vinte.

MARY L. DANiEL

\section{University of Iowa}

7 Antônio Cândido, "O Sertão e o Mundo", Diálogo, No. 8 (novembro, 1957), p. 6. 
